\title{
Testing the Integration of the US and Chinese Stock Markets in a Fama-French Framework
}

\author{
Robert Brooks \\ Monash University \\ Amalia Di Iorio \\ RMIT University \\ Robert Faff \\ Monash University \\ Yuenan Wang \\ RMIT University
}

\begin{abstract}
This paper explores the integration/segmentation between the US and Chinese stock markets. Our analysis extends the work of Jorion and Schwartz (1986) to a Fama-French framework using both Chinese and US Fama-French factors. Despite the ongoing liberalisation process in China our results support the segmentation hypothesis.

- JEL Classification : C32, G12, G15

- Key Words: market segmentation, French-Fama, Chinese stock market, GMM

\footnotetext{
*Robert Brooks : Department of Econometrics and Business Statistics, Monash University, Amalia Di Iorio: School of Economics, Finance \& Marketing, RMIT University, GPO Box 2476V, Melbourne, Victoria, 3001, Australia, Tel: +61-3-9925 5900, Fax: +61-3-9925 5986, e-mail: amalia.diiorio@rmit.edu.au, Robert Faff : Department of Accounting and Finance, Monash University, Yuenan Wang: School of Economics, Finance and Marketing, RMIT.

(C2009-Center for International Economics, Sejong Institution, All Rights Reserved.
} 


\section{Introduction}

The Chinese economy has undergone spectacular growth in recent decades, and as part of an ongoing liberalisation process is now opening its stock markets to greater foreign investment. By the end of September 2006, 48 foreign institutions had been granted Qualified Foreign Institutional Investor status in China, and the combined investment quota granted to them totalled US $\$ 7.845$ billion. ${ }^{1}$ Given this background, our primary research question is straightforward: is the Chinese capital market integrated into mainstream global markets? Specifically, we explore the capital market integration between the US and Chinese markets. Notably, our analysis extends the work of Jorion and Schwartz (1986) to a Fama-French framework using both Chinese and US Fama-French factors.

With the substantial progress toward financial market deregulation and liberalisation across the world, interest in testing global financial market integration has been mounting over the last two decades. Due to the attraction of the capital asset pricing model (CAPM) in that it offers powerful and intuitively appealing predictions about how to measure risk and the relation between expected return and risk, the application of the CAPM in the testing of integration has been prevalent. If there is a world market portfolio that is mean-variance efficient and the world market is integrated, assets with the same sensitivities to movements in the world market portfolio should receive the same price, irrespective of their nationalities. Examples of such tests can be found in Solnik (1977), Stulz (1984), Jorion and Schwartz (1986) and Harvey and Zhou (1993) among many others.

However, an enormous volume of literature presenting less favourable evidence on the CAPM has evolved since the development of the model in the 1960s. The rejection of the CAPM may be spurious due to the efficacy of testing methodologies. ${ }^{2}$ Nevertheless, the bulk of the existing research suggests that one or more additional factors may be required to characterize the behaviour of expected returns [e.g. Miller (1999)]. Consequently, the deficiencies inherent in earlier empirical tests of capital market integration and segmentation could be rectified by modifying the test to utilise the more general and less restrictive international

\footnotetext{
${ }^{1}$ Data source: Asia Times, 22 Sep 2006. For more information about these opening policies in China, please refer to Yeo (2003)

${ }^{2}$ There are arguments that the CAPM may be spuriously rejected because of the use of poor proxies for the market portfolio [e.g. Roll (1977), and Kandel and Stambaugh (1995)] and data snooping and biases [e.g. MacKinlay (1995) and Kothari and Shanken (1995)].
} 
multifactor asset-pricing models. An important ingredient for in this approach is to identify some specific factors likely to explain the cross-section of expected returns.

Mittoo (1992) uses two groups of factors to analyse the integration between the Canadian and US markets. One group contains five pre-specified economic variables while the other group are factors extracted using the full covariance matrix of stock returns. Interestingly, she finds evidence when using both the CAPM and Arbitrary Pricing Theory (APT) that suggests increasing integration between the Canadian market and the US market. Tests of market integration using the multifactor asset-pricing framework can also be found in Cho, Eun and Senbet (1986), Gultekin, Gultekin and Penati (1989) and Choi and Rajan (1997). A popular alternative choice of multi-factor model is the three-factor model proposed by Fama and French (1993), however, to date, integration tests that are based on the Fama and French (1993) three-factor model have received little attention in the literature.

As argued by Fama and French (1993, 1995, 1996, 1998), the empirical successes of their three-factor model suggests that it is an equilibrium asset pricing model, and therefore a three-factor version of the Intertemporal CAPM or the APT could also be developed. The three-factor model is developed from the bulk of evidence that size and the book-to-market ratios are among the most important firm measures capable of capturing variation in stock returns [e.g. Arshanapalli, Coggin and Doukas (1998); and Barry, Goldreyer, Lockwood and Rodriguez (2002)].

Since the advent of the three-factor model, there has been intense debate over its validity relative to the CAPM. Controversies surrounding the model itself have also emerged. Faff (2004) provides a good discussion of various aspects of the three-factor model. Faff (2004) divides the relevant literature into eight categories, which contends that data dredging, econometric issues and seasonal effects all bias the results towards the three-factor model. However, Fama and French (2004, 2005 ) present a good defence of their model. By using an updated sample, they confirm their earlier evidence that the relation between beta and average return is flat in the US market. They argue against sample specific problems, and point out that the empirical failings of the CAPM cannot be justified by investors' irrational behaviour.

In this paper, we use an augmented Fama and French three-factor model to examine the integration between the US and the Chinese A-share market. Due to its exceptionally strong economic performance and relaxation of market 
regulations, the Chinese stock market has attracted the attention of global investors in recent years. Accordingly, a focus on China is of self-evident importance. In addition, evidence of regional market integration has also been found. For example, Wang and Di Iorio (2006a) suggest that the A-share market has been moving from segmentation to integration with the Hong Kong stock market. It is likely that the pricing of A-shares has also been influenced by their U.S counterparts due to market liberalisation in China and the strong economic ties between these two countries.

The implementation of the Fama and French three-factor model to test of the integration hypothesis in the Chinese stock market is motivated by several other studies. For example, Drew, Naughton and Veeraraghavan (2003) suggest that the Fama and French three-factor model explains the behaviour of stock returns better than the CAPM for the stocks listed in the Shanghai stock exchange. Similarly, Wang and Di Iorio (2006b) show using a cross-sectional regression approach, that firm size and the book-to-market ratio are the most significantly priced factors in the A-share.

Our analysis confirms previous results suggesting that there is a negative relation between size and average return, and there is an even stronger positive relationship between the book-to-market ratio and the average return in A-shares. Further, we find that the Fama and French three-factor model largely captures the average returns on Chinese stock portfolios constructed on firm size and book-to-market ratio. The tests of market integration vs. segmentation suggest that over the sample period, the Chinese stock market is completely segmented from the US market. Only pure domestic factors are priced in A-shares. Sub-period tests show that despite the stronger economic links, the A-share market is not becoming increasingly integrated with the US market.

The organization of the remainder of the paper is as follows. In the next section, we describe the data and derive the international version of the Fama and French three-factor model. Section III presents and discusses the empirical results. Section IV concludes the paper.

\section{Data Description and Methodology}

\section{A. Data}

The monthly closing prices for the Shanghai A-share index and the Shenzhen Ashare index from July 1993 through June 2006, are obtained from the Datasteam 
database. By assigning a value weight on each index, we estimate the valueweighted Chinese A-share index which includes all A-shares listed in mainland China. The monthly stock prices and the accounting data on all Chinese individual A-shares traded on both the Shanghai Stock Exchange and the Shenzhen Stock Exchange for the same sample period are also collected from the same database.

The following variables are created for each firm in each month:

(i) monthly stock returns, defined as the logarithm of the monthly price relative;

(ii) size, defined as the product of the closing stock price and the number of shares outstanding; ${ }^{3}$

(iii) $\mathrm{BM}$, defined as the reciprocal of the monthly ratio of the market-to-book value. The market-to-book ratio is calculated by the database as a firm's monthly market value divided by its book value in the previous fiscal year. ${ }^{4}$

Following Fama and French (1992, 1993), we form six portfolios by sorting individual A-shares according to size and $\mathrm{BM}$ each month. We subsequently use these portfolios to construct portfolios that mimic the underlying risk factors related to size and the book-to-market ratio. At the end of June of each year $t$, stocks are assigned to two portfolios of size (small and big) based on the median A-share size. ${ }^{5}$ We also divide stocks at the same time into three BM groups based on the now conventional breakpoints for the bottom $30 \%$ (low), middle $40 \%$ (median) and top 30\% (high) of the ranked values of BM. The six portfolios (S/L, $\mathrm{S} / \mathrm{M}, \mathrm{S} / \mathrm{H}, \mathrm{B} / \mathrm{L}, \mathrm{B} / \mathrm{M}$ and $\mathrm{B} / \mathrm{H}$ ) are then constructed from the intersections of the two size portfolios and the three BM portfolios. Like Fama and French (1993), we do not include negative BM firms or firms that have been listed for less than two years. Value-weighted monthly returns on the six portfolios are calculated from July in year $t$ to June in year $t+1$.

Table 1 reports the descriptive statistics for the six stock portfolios in the Chinese A-share market. It shows that the portfolios with the lowest book-tomarket ratios generated negative average returns during our sample period while the average returns for all the other portfolios are positive. The positive relationship

\footnotetext{
${ }^{3} \mathrm{We}$ use the total number of shares outstanding to calculate market value. There used to be a large number of non-tradable shares in the Chinese A-share market. However, in 2005 the share-merger reform was implemented to resolve this problem

${ }^{4}$ Some data errors in BM, which may occur where the database carries insufficient significant digits, are corrected by manually extracting the relevant information from the annual reports found on the web site http://www.cninfo.com.cn/default.htm

${ }^{5}$ Chinese A-share companies are required to release their annual financial statements within four months of the end of their financial year (December).
} 
Table 1. Descriptive Statistics for Six Portfolios Formed on Size and Book-to-market Ratio in the Chinese Stock Market: 1995-2006 ${ }^{\mathrm{a}}$

\begin{tabular}{ccccccc}
\hline & $\mathrm{S} / \mathrm{L}$ & $\mathrm{S} / \mathrm{M}$ & $\mathrm{S} / \mathrm{H}$ & $\mathrm{B} / \mathrm{L}$ & $\mathrm{B} / \mathrm{M}$ & $\mathrm{B} / \mathrm{H}$ \\
\hline Avg. No of Stocks & 64.09 & 80.82 & 56.18 & 55.73 & 80.18 & 65.27 \\
Mean Return & -0.141 & 0.207 & 0.445 & -0.302 & 0.073 & 0.509 \\
Std of Return & 4.221 & 3.935 & 4.319 & 3.494 & 3.789 & 3.747 \\
$t$-stat (mean) & -0.384 & 0.603 & 1.184 & -0.992 & 0.222 & 1.559 \\
\hline
\end{tabular}

${ }^{a}$ The portfolios are constructed according to size [small (S) \& big (B)] and book-to-market ratio [low (L), middle (M) \& top $(\mathrm{H})]$ for each month in the sample.

between average return and book-to-market ratio is consistent. However, none of the portfolios have monthly returns that are statistically significantly different from zero.

The three explanatory variables in the Chinese stock market are then defined as follows:

(i) Excess market return $r_{m c}$, representing the domestic market factor in stock returns. It is defined as the logarithm of the monthly price relative of the valueweighted A-share index minus a proxy for the risk-free rate of return in the Chinese stock market (the 3-month Time Deposit Rate for China, obtained from Datastream $^{6}$ );

(ii) $\mathrm{SMB}_{\mathrm{c}}$, the domestic size mimicking portfolio, defined as the difference each month between the average of the returns of the three small stock portfolios $(\mathrm{S} /$ $\mathrm{L}, \mathrm{S} / \mathrm{M}$ and $\mathrm{S} / \mathrm{H}$ ) and the average of the returns of the three big stock portfolios $(\mathrm{B} / \mathrm{L}, \mathrm{B} / \mathrm{M}$ and $\mathrm{B} / \mathrm{H})$;

(iii) $\mathrm{HML}_{\mathrm{c}}$, the domestic $\mathrm{BM}$ mimicking portfolio, defined as the difference each month between the average of the returns of the two high BM stock portfolios $(\mathrm{S} / \mathrm{H}$ and $\mathrm{B} / \mathrm{H})$ and the average of the returns of the two low BM stock portfolios (S/L and $\mathrm{B} / \mathrm{L})$.

The counterpart Fama-French factors for the US stock market are obtained directly from the Kenneth R. French data library. Since the issue of currency risk is simplified by assuming exchange rate uncertainty is not priced separately from the market risk, the three US factors are converted into RMB measures by using the relevant end-of-month exchange rates, which are also sourced from Datastream.

Table 2 presents summary statistics for the Fama-French factor returns in the

${ }^{6} \mathrm{We}$ are careful to convert the data for our risk free proxy to a one-month equivalent, to be compatible with the rest of our analysis. 
Table 2. Summary Statistics for Monthly Returns on Fama and French Factors in Both the US and the Chinese A-share Markets: $1995-2006$

\begin{tabular}{|c|c|c|c|c|c|c|c|c|c|c|c|c|}
\hline & \multirow[b]{3}{*}{ Mean } & \multirow[b]{3}{*}{ Std } & \multirow[b]{3}{*}{$t(m n)$} & \multicolumn{3}{|c|}{ Autocorr. for lag } & \multicolumn{6}{|c|}{ Correlations } \\
\hline & & & & & & & US & & & China & & \\
\hline & & & & 1 & 2 & 12 & $r_{m}$ & SMB & HML & $r_{m}$ & SMB & HML \\
\hline \multicolumn{13}{|c|}{ Panel A: US } \\
\hline$r_{m}$ & 0.586 & 4.490 & 1.500 & 0.031 & -0.052 & 0.009 & 1.000 & & & & & \\
\hline SMB & 0.260 & 4.222 & 0.707 & -0.077 & 0.005 & -0.015 & 0.213 & 1.000 & & & & \\
\hline HML & 0.463 & 3.807 & 1.397 & 0.039 & 0.046 & -0.068 & -0.550 & -0.498 & 1.000 & & & \\
\hline \multicolumn{13}{|c|}{ Panel B: China } \\
\hline$r_{m}$ & 0.146 & 3.430 & 0.490 & 0.080 & 0.065 & -0.062 & 0.016 & 0.066 & 0.032 & 1.000 & & \\
\hline SMB & 0.077 & 1.668 & 0.530 & -0.007 & -0.094 & -0.008 & -0.077 & -0.176 & 0.164 & 0.149 & 1.000 & \\
\hline HML & 0.698 & 1.994 & 4.023 & 0.092 & -0.091 & 0.172 & -0.017 & -0.010 & 0.044 & 0.083 & -0.184 & 1.000 \\
\hline
\end{tabular}


two stock markets, covering the period 1995 to 2006 . The results show that the average value of the excess US market return is $0.586 \%$ per month, which is more than triple that of the Chinese A-share market counterpart (0.146\%). Notably, over the full sample period neither excess market return is statistically different from zero. The average SMB return in the US market is only $0.26 \%$ per month, while the book-to-market factor, HML, produces an average premium of $0.46 \%$ per month. Neither is significant at the 5\% level. Compared to the results in Fama and French (1993), we find that the US SMB and HML factors are weaker in the more recent period due to their increased volatility. Further, the magnitude of the (negative) correlation between these two factors dramatically higher here: -0.08 in Fama and French (1993) to -0.498 in our sample period. With regard to the Chinese stock market, the higher average return $(0.698 \%)$ and much lower volatility of the domestic HML factor implies that it might be able to capture substantial cross-sectional variation in A-share returns. In addition, none of the autocorrelation coefficients are significant at the 5\% level and the correlations between all six factors are generally low except for those between the US HML and SMB factors, and the US HML and market factors.

As test assets, we form a different set of nine portfolios using firm size and the book-to-market ratio for A-shares. ${ }^{7}$ Employing the same method as described previously to construct the mimicking factor portfolios, this time we use the breakpoints of the bottom $33.33 \%$ and the top $66.67 \%$ for both the size and bookto-market ratio portfolios. Table 3 presents descriptive statistics for the nine portfolios. It shows that in every size classification, both the average monthly returns and their associated t-statistics increase from lower- to higher-BM portfolios, suggesting a strong relationship between the book-to-market ratio and stock returns in China. In contrast, in every BM classification, portfolios containing smaller stocks do not always generate higher monthly returns.

\section{B. Research Method}

For a specific stock market, Fama and French (1993) propose an empirical three-factor asset pricing model as:

\footnotetext{
${ }^{7}$ As explained shortly, the test of integration vs. segmentation based on the augmented Fama and French model requires simultaneous estimation of 6 betas for each portfolio plus 6 factor mean coefficients, or 60 parameters (when a 9 test asset setting is chosen). Considering that the test will also be conducted in two sub-periods and that we have 132 time series observations, nine is the maximum possible number of portfolios that can be feasibly accommodated in the system..
} 
Table 3. Descriptive Statistics for Nine Test Assets - Stock Portfolios Formed on Size and Book-to-market Ratio in the Chinese A-share Market: 1995-2006

\begin{tabular}{|c|c|c|c|c|c|c|}
\hline \multirow{2}{*}{$\begin{array}{c}\text { Size } \\
\text { groupings }\end{array}$} & \multicolumn{6}{|c|}{ Book-to-market Ratio (BM) Groupings } \\
\hline & Low & Medium & High & Low & Medium & High \\
\hline & \multicolumn{3}{|c|}{$\begin{array}{l}\text { Average of Annual Averages of } \\
\text { Firm Size (mil.RMB) }\end{array}$} & \multicolumn{3}{|c|}{$\begin{array}{c}\text { Average of Annual Averages of } \\
\text { Book-to-market Ratio }\end{array}$} \\
\hline Small & 1129 & 1135 & 1071 & 0.168 & 0.308 & 0.514 \\
\hline Medium & 2064 & 2076 & 2083 & 0.165 & 0.308 & 0.518 \\
\hline \multirow[t]{2}{*}{ Big } & 6456 & 5986 & 4769 & 0.166 & 0.305 & 0.544 \\
\hline & \multicolumn{3}{|c|}{$\begin{array}{c}\text { Average of Annual Number of } \\
\text { Firms in Portfolio }\end{array}$} & \multicolumn{3}{|c|}{$\begin{array}{l}\text { Average of Monthly Returns of } \\
\text { Firms in Portfolio (percent) }\end{array}$} \\
\hline Small & 53.82 & 44.64 & 35.73 & 0.131 & 0.289 & 0.421 \\
\hline Medium & 35.18 & 43.55 & 55.18 & -0.372 & 0.130 & 0.365 \\
\hline \multirow[t]{2}{*}{ Big } & 45.45 & 45.00 & 43.73 & -0.404 & 0.148 & 0.463 \\
\hline & Ret & Skewness of Monthly & y & \multicolumn{3}{|c|}{$\begin{array}{l}\text { Kurtosis of Monthly } \\
\text { Returns of Firms in Portfolio }\end{array}$} \\
\hline Small & 0.472 & 0.006 & 0.787 & 4.320 & 3.789 & 4.233 \\
\hline Medium & 0.494 & 0.427 & 0.941 & 3.308 & 3.465 & 6.358 \\
\hline \multirow[t]{2}{*}{ Big } & 0.129 & 0.640 & 1.218 & 3.047 & 5.793 & 7.670 \\
\hline & \multicolumn{3}{|c|}{$\begin{array}{l}\text { Standard Deviation of Monthly } \\
\text { Returns of Firms in Portfolio }\end{array}$} & \multicolumn{3}{|c|}{$\begin{array}{l}t \text {-statistic for Average } \\
\text { Monthly Returns }\end{array}$} \\
\hline Small & 4.461 & 4.188 & 4.197 & 0.337 & 0.793 & 1.152 \\
\hline Medium & 4.010 & 4.011 & 3.994 & -1.066 & 0.372 & 1.050 \\
\hline Big & 3.439 & 3.931 & 4.353 & -1.350 & 0.433 & 1.222 \\
\hline
\end{tabular}

where $E\left(r_{i}\right)$ is the expected excess return of asset $i$; $E\left(r_{m}\right)$ is the expected excess return on the market portfolio; $E(S M B)$ is the expected return on the mimicking portfolio for the size factor; and $E(H M L)$ is the expected return on the mimicking portfolio for the book-to-market factor.

A simple test of this three-factor model can be conducted by using its empirical counterpart:

$$
r_{i t}=a_{i}+b_{i} r_{m t}+s_{i} S M B_{t}+h_{i} H M L_{t}+\mu_{i t}
$$

where $r_{i t}$ and $r_{m t}$ denote realized excess returns for asset $i$ and the market, respectively. After applying expectations to equation (2) and comparing it to the model of equation (1), we observe the standard zero intercept restriction that constitutes the null hypothesis: $H_{0}: a_{i}=0$, for $i=1,2, \ldots, N$. Following Faff (2003, $2004)$, the tests are modified to allow a direct estimation of the premia by 
modelling the mean of the Fama and French risk factors:

$$
\begin{gathered}
r_{i t}=b_{i} r_{m t}+s_{i} S M B_{t}+h_{i} H M L_{t}+\mu_{i t} \quad[i=1,2, \ldots, N] \\
r_{m t}=\lambda_{m}+\varepsilon_{l} \\
S M B_{t}=\lambda_{S M B}+\psi_{t} \\
H M L_{t}=\lambda_{H M L}+\omega_{t}
\end{gathered}
$$

The GMM approach of MacKinlay and Richardson (1991) is then used for the test. As suggested by MacKinlay and Richardson (1991), the GMM based tests are valid under much weaker distributional assumptions than most previous tests. Their tests show that misspecified distributional assumptions can have a quantifiably adverse effect on statistical inference. In our test, the empirical system of equations (3) to (6) involves $4 \mathrm{~N}+3$ sample moment equations, with $3 \mathrm{~N}+3$ unknown parameters. Thus, the GMM statistic involves $\mathrm{N}$ over-identifying restrictions and they are tested using: ${ }^{8}$

$$
G M M=(T-N-1)^{*} g T(\hat{\phi})^{\prime} \cdot S_{T}^{1} \cdot g T(\hat{\phi})
$$

where $g T(\hat{\phi})=\frac{1}{T} \sum \frac{T}{t=1} f_{t}(\hat{\phi})$ is the empirical moment condition vector.

In the context of this system of equations, in addition to the basic GMM test outlined above, the test of the hypotheses that each expected premium is zero, i.e. $H_{0}: \lambda_{m}=0 ; H_{0}: \lambda_{S M B}=0$; and $H_{0}: \lambda_{H M L}=0$, are also performed.

Next, following Jorion and Schwartz (1986), we consider two competing models of asset pricing for Chinese A-shares. In the framework of an international version of the Fama and French (1993) three-factor model, if the US and the Chinese stock markets are integrated, the only priced factors for a Chinese A-share are the index return on the US market, $\mathrm{SMB}_{u}$ and $\mathrm{HML}_{u}$. Hence, under this scenario of full integration the returns on asset $i$ in the Chinese A-share market are determined by the following model:

$$
\tilde{R}_{i t}=E\left(\tilde{R}_{i t}\right)+\beta_{i 1} R_{U t}+\beta_{i 2} S M B_{U t}+\beta_{i 3} H M L_{U T}+\mu_{i t}
$$

where $\tilde{R}_{i t}$ is the random return of the $i$ th asset for the period ending at time $t$; $E\left(\tilde{R}_{i t}\right)$ is the rational expectation of the random return of asset $i$ given information

\footnotetext{
${ }^{8}$ This represents the small-sample adjusted versioR following MacKinlay and Richardson (1991). Our estimation technique also employs heteroskedasticity and autocorrelation consistent covariance matrices and uses an iterated procedure following Ferson and Foerster (1994). The GMM test statistic is asymptotically distributed as chi-squared with $\mathrm{N}$ degrees of freedom.
} 
at the beginning of time $t ; \tilde{R}_{U t}$ is the US market return; $S M B_{U t}$ and $H M L_{U t}$ are the other two explanatory factors as defined earlier.

Assuming no arbitrage opportunities and some additional conditions (see Connor (1984)), the expected return on asset $i$ can be written as:

$$
E\left(\tilde{R}_{i t}\right)=\lambda_{0 t}+\lambda_{1} \beta_{i 1}+\lambda_{2} \beta_{i 2}+\lambda_{3} \beta_{i 3}
$$

where $\lambda_{j}, j=1,2,3$, are the price premia associated with the three factors at time $t$, and $\lambda_{0 t}$ is the risk-free rate in period $t$.

The empirical version of the model is formulated by substituting (9) into (8):

$$
\tilde{R}_{i t}=\lambda_{0 t}+\beta_{i 1}\left(\tilde{R}_{U t}+\lambda_{1}\right)+\beta_{i 2}\left(S M B_{U t}+\lambda_{2}\right)+\beta_{i 3}\left(H M L_{U t}+\lambda_{3}\right)+\mu_{i t}
$$

To test the integration hypothesis, the complete international versions of the Fama and French three-factor model described by equation (9) is augmented to allow for the possible influence and pricing of the three domestic Chinese factors. The augmented system becomes:

$$
\begin{aligned}
\tilde{R}_{i t}= & \lambda_{0 t}+\beta_{i 1}\left(\tilde{R}_{U t}+\lambda_{1}\right)+\beta_{i 2}\left(S M B_{U t}+\lambda_{2}\right)+\beta_{i 3}\left(H M L_{U t}+\lambda_{3}\right) \\
& +\beta_{i 4}\left(\tilde{R}_{C t}+\lambda_{4}\right)+\beta_{i 5}\left(S M B_{C t}+\lambda_{5}\right)+\beta_{i 6}\left(H M L_{C t}+\lambda_{6}\right)+\mu_{i t}
\end{aligned}
$$

where $\tilde{R}_{C t}$ is value-weighted market return in the Chinese A-share market; and $\lambda_{j}, j$ $=4,5,6$, are the price of risk associated with the three domestic factors.

Since one country's national factors may constitute some non-significant portion of the international factors, we follow Jorion and Schwartz (1986) and Gultekin, Gultekin and Penati (1989) to isolate in the domestic factors the component which is independent of their international counterparts by taking orthogonal projections. Therefore, the model implied by integration can be reformulated as:

$$
\begin{aligned}
\tilde{R}_{i t}= & \lambda_{0 t}+\beta_{i 1}\left(\tilde{R}_{U t}+\lambda_{1}\right)+\beta_{i 2}\left(S M B_{U t}+\lambda_{2}\right)+\beta_{i 3}\left(H M L_{U t}+\lambda_{3}\right) \\
& +\beta_{i 4}\left(\tilde{R}_{C t}^{U t}+\lambda_{4}\right)+\beta_{i 5}\left(S M B_{C t}^{U t}+\lambda_{5}\right)+\beta_{i 6}\left(H M L_{C t}^{U t}+\lambda_{6}\right)+\mu_{i t}
\end{aligned}
$$

where $\tilde{R}_{C t}^{U t}, S M B_{C t}^{U t}$ and $H M L_{C t}^{U t}$ are the fitted values obtained from the three projections, respectively, and are used as measures of the pure domestic factors.

The hypothesis of complete integration can be tested by examining whether the $\lambda_{j}, j=4,5,6$, are jointly equal to zero. Partial integration is easily tested by examining whether some of these $\lambda$ s are significantly different from zero or not.

Conversely, to test the segmentation hypothesis, the domestic Fama and French model is augmented to allow for the possible influence and pricing of the three US 
factors as follows:

$$
\begin{aligned}
\tilde{R}_{i t}= & \delta_{0 t}+\alpha_{i 1}\left(\tilde{R}_{C t}+\delta_{1}\right)+\alpha_{i 2}\left(S M B_{C t}+\delta_{2}\right)+\alpha_{i 3}\left(H M L_{C t}+\delta_{3}\right) \\
& +\alpha_{i 4}\left(\tilde{R}_{U t}^{C t}+\delta_{4}\right)+\alpha_{i 5}\left(S M B_{U t}^{C t}+\delta_{5}\right)+\alpha_{i 6}\left(H M L_{U t}^{C t}+\delta_{6}\right)+\varepsilon_{i t}
\end{aligned}
$$

where $\tilde{R}_{U t}^{C t}, S M B_{U t}^{C t}$ and $H M L_{U t}^{C t}$ are the three pure international factors obtained by a group of projections. The hypothesis of complete segmentation and the hypothesis of partial segmentation are easily tested by examining whether all or some $\delta j, j=4,5,6$, are significantly different from zero or not.

We use the iterated non-linear seemingly unrelated regression (NSUR) technique to estimate the system of equations (12) and (13). The NSUR estimator has a full error covariance matrix. As shown by Gallant (1985), the NUSR estimator is strongly consistent and asymptotically normal, even in the absence of normally distributed errors. If the errors are normally distributed, this estimator is also the maximum likelihood estimator. The GMM test is also employed to test integration vs. segmentation by relaxing the assumption of the normality of asset returns.

\section{Empirical Results}

Initially, we consider the outcome of unrestricted Fama and French time series regressions of equation (2) across the nine portfolios. ${ }^{9}$ We report a summary of the estimated factor loadings in panel A of Table 4. The major features worthy of note from this table are as follows. First, according to Merton (1973), if the multifactor model is parsimonious and describes return in a meaningful manner, the intercept should be statistically indistinguishable from zero. Our tests show that three out of nine intercepts are statistically significant from zero at the 5\% level. Second, for all portfolios, the market betas are close to unity and are highly significant at the $1 \%$ level. Third, all the portfolios in the small and medium size categories have positive and significant SMB betas. However, the SMB betas for the portfolios in the large size grouping are all negative but not significant. Fourth, a high proportion of HML betas are also statistically significant. Similar to Drew et al. (2003), we find that some of the HML betas are significantly negative (low BM portfolios). The above results suggest that the behaviour of beta, SMB and HML coefficients in the Chinese setting is generally consistent with the findings of Fama

\footnotetext{
${ }^{9}$ As a preliminary analysis prior to performing the asset pricing tests in only the Chinese stock market outlined earlier, we rule out the possibility of 'useless' factor in the spirit of Kan and Zhang (1999). Wald tests of these hypotheses reveal strong rejection of the null hypotheses.
} 
Table 4. Tests of the Fama and French Three-factor Model in the Chinese A-share Market: 1995-2006

This table, in Panel A, presents the results of testing the three-factor model:

$$
r_{i t}=\alpha_{i}+b_{i} r_{m t}+s_{i} S M B_{t}+h_{i} H M L_{t}+\mu_{i t}
$$

and in Panel B the systems GMM estimation:

$$
\begin{aligned}
& r_{i t}=b_{i} r_{m t}+s_{i} S M B_{t}+h_{i} H M L_{t}+\mu_{i t} \quad[i=1,2, \ldots, N] \\
& r_{m t}=\lambda_{m}+\varepsilon_{t} \\
& S M B_{t}=\lambda_{S M B}+\Psi_{t} \\
& H M L_{t}=\lambda_{H M L}+\omega_{t}
\end{aligned}
$$

\begin{tabular}{|c|c|c|c|c|c|c|}
\hline \multicolumn{7}{|c|}{ Panel A: Ordinary Least Squares Estimation } \\
\hline \multirow[t]{2}{*}{ Size } & \multicolumn{6}{|c|}{ Book-to-market Ratio (BE/ME) } \\
\hline & Low & Medium & High & Low & Medium & High \\
\hline \multirow[b]{2}{*}{ Small } & \multicolumn{3}{|c|}{$\mathrm{a}$} & \multicolumn{3}{|c|}{$\mathrm{a}(t)$} \\
\hline & -0.296 & -0.182 & -0.282 & -1.493 & -0.984 & -1.610 \\
\hline Medium & -0.438 & -0.132 & -0.379 & -2.861 & -0.692 & -2.403 \\
\hline \multirow[t]{2}{*}{ Big } & -0.530 & -0.257 & -0.272 & -3.628 & -1.355 & -1.048 \\
\hline & \multicolumn{3}{|c|}{$\mathrm{b}$} & \multicolumn{3}{|c|}{$\mathrm{b}(t)$} \\
\hline Small & 0.890 & 0.882 & 0.889 & 16.081 & 17.054 & 18.164 \\
\hline Medium & 0.953 & 0.942 & 0.911 & 22.304 & 17.659 & 20.705 \\
\hline \multirow[t]{2}{*}{ Big } & 0.889 & 0.978 & 0.887 & 21.804 & 18.419 & 12.220 \\
\hline & \multicolumn{3}{|c|}{$\mathrm{s}$} & \multicolumn{3}{|c|}{$\mathrm{s}(t)$} \\
\hline Small & 1.225 & 1.017 & 0.986 & 10.610 & 9.417 & 9.655 \\
\hline Medium & 0.594 & 0.474 & 0.644 & 6.668 & 4.263 & 7.010 \\
\hline \multirow[t]{2}{*}{ Big } & -0.005 & -0.047 & -0.147 & -0.057 & -0.424 & -0.972 \\
\hline & \multicolumn{3}{|c|}{$\mathrm{h}$} & \multicolumn{3}{|c|}{$\mathrm{h}(t)$} \\
\hline Small & -0.015 & 0.074 & 0.408 & -0.156 & 0.834 & 4.817 \\
\hline Medium & -0.476 & -0.178 & 0.499 & -6.433 & -1.928 & 6.555 \\
\hline \multirow[t]{2}{*}{ Big } & -0.310 & 0.076 & 0.580 & -4.394 & 0.835 & 4.617 \\
\hline & \multicolumn{3}{|c|}{$R^{2}$} & \multicolumn{3}{|c|}{ DW } \\
\hline Small & 0.776 & 0.777 & 0.801 & 2.176 & 2.476 & 2.729 \\
\hline Medium & 0.835 & 0.742 & 0.822 & 2.360 & 2.530 & 2.306 \\
\hline Big & 0.795 & 0.733 & 0.590 & 2.723 & 2.384 & 1.846 \\
\hline \multicolumn{7}{|c|}{ Panel B: System GMM Estimation } \\
\hline \multirow{3}{*}{ Jul.95-Jun.06 } & $\mathrm{GMM}^{\mathrm{a}}$ & $\lambda \mathrm{m}^{\mathrm{b}}$ & $\lambda \mathrm{SMB}^{\mathrm{b}}$ & $\lambda \mathrm{HML}^{\mathrm{b}}$ & & \\
\hline & 7.193 & 0.210 & 0.089 & 0.728 & & \\
\hline & $(0.617)$ & $(0.776)$ & $(0.800)$ & $(4.558)$ & & \\
\hline \multirow[t]{2}{*}{ Jul.95-Dec.00 } & 5.671 & 0.550 & 0.110 & 1.024 & & \\
\hline & $(0.772)$ & $(1.331)$ & $(0.713)$ & $(4.205)$ & & \\
\hline \multirow[t]{2}{*}{ Jan.01-Jun.06 } & 10.002 & -1.435 & -0.407 & 0.773 & & \\
\hline & $(0.350)$ & $(-5.177)$ & $(-4.087)$ & $(8.907)$ & & \\
\hline
\end{tabular}

a The generalized method of moments test statistic (GMM) testing that the three-factor model holds, is distributed as a chi-square with $\mathrm{N}$ degrees of freedom. The associated $p$-value is contained in parentheses below the statistic.

${ }^{\mathrm{b}}$ The associated $t$-statistic is contained in parentheses below the coefficient estimate. 
and French (1993, 1996).

Panel B of Table 4 presents the test results of the Fama and French three-factor model using the estimation of the system of equations given by equations (3) to (6). To provide additional insights, the full sample period is arbitrarily split into two equal sub-periods. The major features of this panel can be summarised as follows. First, based on the outcome of the GMM test statistics, in all instances the three-factor model cannot be rejected at any conventional level of significance. Second, in the latter sub-period (Jan. 2001 to Jun. 2006) all three estimated premia (market risk, SMB and HML) are statistically significant at the $1 \%$ level, though the coefficients for the market risk and SMB factor are negative. As suggested by Wang and Di Iorio (2006b), the significantly negative market risk premium in the second sub-period may be partly associated with the government's crackdown on illegal market activities and the subsequent plunge in stock prices that may have been manipulated by institutional investors. Generally, on the basis of our findings reported in Table 4, we can conclude that the Fama and French three-factor model is strongly supported. However, of the three factors, we find that it is the HML factor that most often produces a significant and positive estimated risk premium.

The estimated risk premia and their associated $t$-values produced by NSUR estimation of the international version of the Fama and French model given by equations (12) and (13), are reported in Table 5. In the test of market integration between the US and the Chinese stock markets (Panel A), the three international (US) factors and the counterpart domestic factors (orthogonalised) are the independent variables of the model, and the nine equally weighted portfolios are the dependent variables. For the full sample period from July 1995 to June 2006, only the domestic component of the HML factor is significantly priced whereas no US factors are statistically significant. Therefore, the complete integration hypothesis where some international factor(s) is (are) priced and all pure domestic factors are not priced is strongly rejected in favour of market segmentation. To test whether the Chinese stock market is becoming more integrated relative to the US market, sub-period estimates of the risk premiums are presented. For the first subperiod (July 1995 to December 2000), once again the pure domestic HML factor is priced at the $1 \%$ level. Surprisingly, in the second sub-period, none of these factors are statistically significant. The $\chi^{2}$ - statistic of the second sub-period test cannot reject the null hypothesis that the prices of risk for the pure domestic factors are jointly equal to zero.

The results of market segmentation tests presented in Panel B of Table 5 are 
Table 5. Tests of Market Integration vs. Segmentation between the US and the Chinese Stock Markets in Various Time Periods using NSUR Estimation

This table, in Panel A, presents the results of testing market integration using equation:

$\tilde{R}_{i t}=\lambda_{0 t}+\beta_{i 1}\left(\tilde{R}_{U t}+\lambda_{1}\right)+\beta_{i 2}\left(S M B_{U t}+\lambda_{2}\right)+\beta_{i 3}\left(H M L_{U t}+\lambda_{3}\right)+\beta_{i 4}\left(\tilde{R}_{C t}^{U t}+\lambda_{4}\right)+\beta_{i 5}\left(S M B_{C t}^{U t}+\lambda_{5}\right)+\beta_{i 6}\left(H M L_{C t}^{U t}+\lambda_{6}\right)+\mu_{i t}$ and, in Panel $\mathrm{B}$, the results of testing market segmentation using equation:

$\tilde{R}_{i t}=\delta_{0 t}+\alpha_{i 1}\left(\tilde{R}_{C t}+\delta_{1}\right)+\alpha_{i 2}\left(S M B_{C t}+\delta_{2}\right)+\alpha_{i 3}\left(H M L_{C t}+\delta_{3}\right)+\alpha_{i 4}\left(\tilde{R}_{U t}^{C t}+\delta_{4}\right)+\alpha_{i 5}\left(S M B_{U t}^{C t}+\delta_{5}\right)+\alpha_{i 6}\left(H M L_{U t}^{C t}+\delta_{6}\right)+\varepsilon_{i t}$

\begin{tabular}{|c|c|c|c|c|c|c|c|}
\hline Panel A: Test of Integration & $\lambda_{1}$ & $\lambda_{2}$ & $\lambda_{3}$ & $\lambda_{4}$ & $\lambda_{5}$ & $\lambda_{6}$ & $\chi^{2}(3)^{\mathrm{a}}$ \\
\hline Jul. 1995 - Jun. 2006 & 2.287 & 0.351 & 5.247 & 0.045 & 0.170 & 0.734 & 15.38 \\
\hline Jul. 1995 - Dec. 2000 & 4.334 & -1.387 & 3.639 & 0.262 & -0.145 & 0.901 & 16.93 \\
\hline \multirow[t]{2}{*}{ Jan. 2001 - Jun. 2006} & -26.024 & 2.963 & -5.240 & 0.700 & 0.127 & 1.000 & 1.50 \\
\hline & $(-0.494)$ & $(0.340)$ & $(-0.444)$ & $(0.425)$ & $(0.166)$ & $(0.872)$ & $(0.6822)$ \\
\hline Panel B: Test of Segmentation & $\lambda_{1}$ & $\lambda_{2}$ & $\lambda_{3}$ & $\lambda_{4}$ & $\lambda_{5}$ & $\lambda_{6}$ & $\chi^{2}(3)$ \\
\hline Jul. 1995 - Jun. 2006 & $(-0.773)$ & $(0.861)$ & $(4.978)^{* *}$ & $(0.612)$ & $(0.123)$ & $(1.141)$ & $(0.5920)$ \\
\hline \multirow[t]{2}{*}{ Jul. 1995 - Dec. 2000} & -0.017 & -0.048 & 1.029 & 5.221 & -1.408 & 3.564 & 1.30 \\
\hline & $(-0.025)$ & $(-0.161)$ & $(3.221)^{* *}$ & $(0.711)$ & $(-0.369)$ & $(0.871)$ & $(0.7284)$ \\
\hline \multirow[t]{2}{*}{ Jan. 2001 - Jun. 2006} & -0.042 & -0.079 & 0.816 & -25.187 & 2.928 & -5.300 & 0.24 \\
\hline & $(-0.044)$ & $(-0.081)$ & $(0.655)$ & $(-0.477)$ & $(0.346)$ & $(-0.451)$ & $(0.9712)$ \\
\hline
\end{tabular}

${ }^{a}$ The $\chi^{2}$-statistics have three degrees of freedom and test the null hypothesis that the prices of risk for the pure domestic factors (pure international factors) are jointly equal to zero. The associated $p$-vales are in parentheses.

$* *$ denotes significant at the $5 \%$ level. 
Table 6. Tests of Market integration vs. Segmentation between the US and the Chinese Stock Markets using GMM System Estimation

This table, in Panel A, presents the results of testing market integration using equation:

$\tilde{R}_{i t}=\lambda_{0 t}+\beta_{i 1}\left(\tilde{R}_{U t}+\lambda_{1}\right)+\beta_{i 2}\left(S M B_{U t}+\lambda_{2}\right)+\beta_{i 3}\left(H M L_{U t}+\lambda_{3}\right)+\beta_{i 4}\left(\tilde{R}_{C t}^{U t}+\lambda_{4}\right)+\beta_{i 5}\left(S M B_{C t}^{U t}+\lambda_{5}\right)+\beta_{i 6}\left(H M L_{C t}^{U t}+\lambda_{6}\right)+\mu_{i t}$ And, in Panel $\mathrm{B}$, the results of testing market segmentation using equation:

$\tilde{R}_{i t}=\delta_{0 t}+\alpha_{i 1}\left(\tilde{R}_{C t}+\delta_{1}\right)+\alpha_{i 2}\left(S M B_{C t}+\delta_{2}\right)+\alpha_{i 3}\left(H M L_{C t}+\delta_{3}\right)+\alpha_{i 4}\left(\tilde{R}_{U t}^{C t}+\delta_{4}\right)+\alpha_{i 5}\left(S M B_{U t}^{C t}+\delta_{5}\right)+\alpha_{i 6}\left(H M L_{U t}^{C t}+\delta_{6}\right)+\varepsilon_{i t}$

\begin{tabular}{|c|c|c|c|c|c|c|c|}
\hline Panel A: Test of Integration & $\lambda_{1}$ & $\lambda_{2}$ & $\lambda_{3}$ & $\lambda_{4}$ & $\lambda_{5}$ & $\lambda_{6}$ & $\chi^{2}(3)^{\mathrm{a}}$ \\
\hline \multirow[t]{2}{*}{ Jul. 1995 - Jun. 2006} & 2.059 & -0.371 & 3.814 & -0.063 & 0.186 & 0.809 & 24.01 \\
\hline & $(0.822)$ & $(-0.172)$ & $(1.616)$ & $(-0.365)$ & $(0.964)$ & $(4.718)^{* *}$ & $(0.0000)$ \\
\hline \multirow[t]{2}{*}{ Jul. 1995 - Dec. 2000} & 1.343 & -2.320 & 1.740 & 0.120 & -0.080 & 0.838 & 108.24 \\
\hline & $(0.546)$ & $(-1.165)$ & $(0.893)$ & $(0.375)$ & $(-0.366)$ & $(9.461)^{* *}$ & $(0.0000)$ \\
\hline \multirow[t]{2}{*}{ Jan. 2001 - Jun. 2006} & -7.554 & 4.226 & -0.001 & 0.111 & 0.512 & 0.820 & 15.52 \\
\hline & $(-0.660)$ & $(0.921)$ & $(-0.001)$ & $(0.333)$ & $(1.661)^{*}$ & (1.612) & $(0.0014)$ \\
\hline Panel B: Test of Segmentation & $\lambda_{1}$ & $\lambda_{2}$ & $\lambda_{3}$ & $\lambda_{4}$ & $\lambda_{5}$ & $\lambda_{6}$ & $\chi^{2}(3)$ \\
\hline \multirow[t]{2}{*}{ Jul. 1995 - Jun. 2006} & -0.377 & 0.212 & 0.943 & 2.955 & -0.279 & 3.745 & 5.33 \\
\hline & $(-2.320)^{* *}$ & $(1.712)^{*}$ & $(6.195)^{* *}$ & (1.179) & $(-0.129)$ & $(1.587)$ & $(0.1493)$ \\
\hline \multirow[t]{2}{*}{ Jul. 1995 - Dec. 2000} & -0.205 & 0.081 & 0.899 & 2.234 & -2.284 & 1.674 & 2.70 \\
\hline & $(-0.649)$ & $(0.600)$ & $(7.255)^{* *}$ & $(0.908)$ & $(-1.138)$ & $(0.862)$ & $(0.4406)$ \\
\hline \multirow[t]{2}{*}{ Jan. 2001 - Jun. 2006} & -0.349 & 0.217 & 0.820 & -6.658 & 4.321 & -0.061 & 1.03 \\
\hline & $(-1.733)^{*}$ & (1.189) & $(1.532)$ & $(-0.581)$ & $(0.947)$ & $(-0.029)$ & $(0.7938)$ \\
\hline
\end{tabular}

The $\chi^{2}$-statistics have three degrees of freedom and test the null hypothesis that the prices of risk for the pure domestic factors (pure international factors) are jointly equal to zero. The associated $p$-vales are in parentheses.

$*$ denotes significant at the $10 \%$ level.

$* *$ denotes significant at the $5 \%$ level. 
consistent with our findings for the integration tests. In our full sample period and the first sub-period, only the domestic HML factor is priced. In the second subperiod, we cannot find any factor that is statistically significant at any conventional significance level. However, the fact that we cannot reject the null hypothesis that the prices of risk for the pure international factors are jointly equal to zero suggests that not only is there little influence of the US stock market on the Chinese stock market, but also that there is no movement from segmentation to integration in our sample period.

The test results of integration and segmentation using GMM system estimation are presented in Table 6 . The evidence is consistent with our findings in Table 5. A summary of the notable results is as follows. First, it is observed that although the domestic HML factor is still the most important factor that explains stock returns in China, the effect of domestic market risk and the domestic SMB factor are statistically significant in some instances. Second, the complete segmentation hypothesis, i.e. that some Chinese factor(s) is (are) priced and all pure US factors are not priced, cannot be rejected in any sample period. The evidence is particularly strong during the entire period when all three Chinese factors are priced risks, whereas the prices of risk for the pure US factors are jointly equal to zero. Third, it is encouraging that the domestic version of the SMB factor is found to be statistically significant at the $10 \%$ level and we cannot reject the hypothesis that the prices of risk for the pure international factors are jointly equal to zero in the tests.

\section{Conclusion}

The Chinese A-share market has recently drawn a great deal of attention from global investors given China's strong economic performance and the government's increasingly aggressive policies designed to promote the integration of its domestic stock market with the world stock market. Consequently, the question of whether or not the Chinese stock market is in fact becoming increasingly integrated with other global markets has also attracted significant attention. This has been particularly true following China's accession to the World Trade Organization and the occurrence of the Asian financial crisis. Prior studies that address the integration of the Chinese stock market include Wang and Di Iorio (2006a). who find that the Chinese A-share market is segmented from the world stock market although it is increasingly integrated with the Hong Kong stock market. However, 
there has not been much analysis of stock market integration between China and the US.

In this paper, we test for market integration and segmentation between the Chinese and the US markets using a methodology extending Jorion and Schwartz (1986) and Fama and French (1993). First, we test the Fama and French threefactor model in the Chinese stock market by using monthly data drawn from the Datastream database. Using a sample period extending from 1 July 1995 to 30 June 2006, we use two test methods - (i) a simple test of unrestricted Fama and French regressions and (ii) a GMM system estimation. The evidence obtained is in strong support of the Fama and French three-factor model. In the tests of market segmentation and integration, our results suggest that the domestic factors are significantly, but not consistently, priced and none of the three US factors have an impact on Chinese stock returns. The result is also robust in two sub-period tests where the hypothesis that the price of risks for the pure US factors (pure international factors) are jointly equal to zero cannot be rejected. Hence, these results suggest that the Chinese stock market is segmented from the US market and, further, there is no detectable movement towards integration between them.

When considering the pricing of A-shares, it must be acknowledged that there is a lack of consistently significant risk premium estimates and that the risk premia estimates are negative in several instances. This may be attributed to the market reforms which have been implemented in different areas of the Chinese stock market in a bid to move trading towards a more market-oriented basis. In addition, the government's grip on capital flows is still hampering significant foreign investment in its stock markets, thus further influencing its progress towards market integration.

Received 31 March 2008, Revised 17 June 2008, Accepted 18 June 2008 


\section{References}

Arshanapalli, B., T. D. Coggin and J. Doukas(1998), "Multifactor Asset Pricing Analysis of Internationa Value Investment Strategies", Journal of Portfolio Management, 24, pp. 10-23.

Barry, C. B., E. Goldreyer, L. Lockwood and M. Rodriguez(2002), "Robustness of Size and Value Effects in Emerging Equity Markets, 1985-2000", Emerging Markets Review, 3, pp. 1-30.

Cho, D. C., C. S. Eun and L. W. Senbet(1986), "International Arbitrage Pricing Theory: an Empirical Investigation", Journal of Finance, 41, pp. 313-329.

Choi, J. J. and M. Rajan(1997), "A Joint Test of Market Segmentation and Exchange Risk Factor in International Capital Markets", Journal of International Business Studies, 28, pp. 29-49.

Connor, G.(1984), “A Unified Beta Pricing Theory”, Journal of Economic Theory, 34, pp. 13-31.

Drew, M. E., T. Naughton and M. Veeraraghavan(2003), "Firm Size, Book-to-Market Equity and Security Returns: Evidence from the Shanghai Stock Exchange", Australian Journal of Management, 28, pp. 119-139.

Faff, R.(2003), "Creating Fama and French Factors with Style", Financial Review, 38, pp. 311-322.

Faff, R., (2004), "A Simple Test of the Fama and French Model Using Daily Data: Australian Evidence", Applied Financial Economics, 14, 83-92.

Fama, E. F. and K. R. French(1992), "The Cross-Section of Expected Stock Returns", Journal of Finance, 47, pp. 427-465.

Fama, E. F. and K. R. French(1993), "Common Risk Factors in the Returns on Stocks and Bonds", Journal of Financial Economics, 33, pp. 3-56.

Fama, E. F. and K. R. French(1995), "Size and Book-to-market Factors in Earnings and Returns", Journal of Finance, 50, pp. 131-155.

Fama, E. F. and K. R. French(1996), "Multifactor Explanations of Asset Pricing Anomalies", Journal of Finance, 51, pp. 55-84.

Fama, E. F. and K. R. French(1998), "Value versus Growth: the International Evidence", Journal of Finance, 53, pp. 1975-1999.

Fama, E. F. and K. R. French(2004), "The Capital Asset Pricing Model: Theory and Evidence", Journal of Economic Perspectives, 18, pp. 25-46.

Fama, E. F. and K. R. French(2005), "The Capital Asset Pricing Model: Theory and Evidence", CFA Digest, 35, pp. 49-51.

Ferson, W. E. and S. R. Foerster(1994), "Finite Sample Properties of the Generalized Method of Moments in Tests of Conditional Asset Pricing Models", Journal of Financial Economics, 36, pp. 29-55.

Gallant, R.(1985), "Seemingly Unrelated Nonlinear Regressions", Journal of Econometrics, 3, pp. 35-50. 
Gultekin, M., B. Gultekin and A. Penati(1989), "Capital Controls and International Capital market Segmentation: the Evidence from the Japanese and American Stock Markets", Journal of Finance, 44, pp. 849-870.

Harvey, C. R. and G. Zhou(1993), "International Asset Pricing with Alternative Distributional Specifications", Journal of Empirical Finance, 1, pp. 107-131.

Jorion, P. and E. Schwartz(1986), "Integration vs. Segmentation in the Canadian Stock Market", Journal of Finance, 41, pp. 603-616.

Kan, R. and C. Zhang(1999): "Two-pass Tests of Asset Pricing Models with Useless Factors", Journal of Financial Economics, 54, pp. 103-127.

Kandel, S. and R. F. Stambaugh(1995), "Portfolio Inefficiency and the Cross-section of Expected Returns," Journal of Finance, 50, pp. 157-184.

Kothari, S. P. and J. Shanken(1995), "Another Look at the Cross-section of Expected Stock Returns", Journal of Finance, 50, pp. 185.

MacKinlay, A. C.(1995), "Multifactor Models Do Not Explain Deviations from the CAPM", Journal of Financial Economics, 38, pp. 3-28.

MacKinlay, A. C. and M. P. Richardson(1991), "Using Generalized Method of Moments to Test Mean-Variance Efficiency", Journal of Finance, 46, pp. 511-527.

Merton, R. C.(1973), “An Intertemporal Capital Asset Pricing Model”, Econometrica, 41, pp. 867-888.

Miller, M. H.(1999), “The History of Finance”, Journal of Portfolio Management, 25, pp. 95-101.

Mittoo, U. R.(1992), "Additional Evidence on Integration in the Canadian Stock Market", Journal of Finance, 47, pp. 2035-2054.

Roll, R.(1977), "A Critique of the Asset Pricing Theory's Tests Part I: on Past and Potential Testability of the Theory", Journal of Financial Economics, 4, pp. 129-176.

Solnik, B.(1977), "Testing International Asset Pricing Models: Some Pessimistic Views", Journal of Finance, 32, p. 503-512.

Stulz, R. M.(1984), "Pricing Capital Assets in an International Setting: an Introduction", Journal of International Business Studies, 15, pp. 55-73.

Wang, Y. and A. Di Iorio(2007a), "Are the China-related Stock Markets Segmented with both World and Regional Stock Markets?," Journal of International Financial Markets, Institutions and Money, 17(3), pp 277-290.

Wang, Y. and A. Di Iorio(2007b), "The Cross Section of Expected Stock Returns in the Chinese A-share Market", Global Finance Journal, 17(3), pp 335-349.

Yeo, S.(2003), "The PRC Qualified Foreign Institutional Investors Market”, China Economic Review, 14, p. 443-450. 